\title{
ПРОБЛЕМЫ ОРГАНИЗАЦИИ ВНУТРЕННЕЙ СИСТЕМЫ ОЦЕНКИ КАЧЕСТВА ОБРАЗОВАНИЯ
}

\section{ORGANIZATIONAL PROBLEMS \\ OF THE INTERNAL SYSTEM \\ FOR THE ASSESSMENT OF EDUCATIONAL QUALITY}

M. Gumerova

G. Khaliullina

Summary: On the one hand, implemention of legal requirements is necessary for ensurance of high level of education, and on the other hand, mechanisms and tools for internal education quality assessment system organization have not been worked out. This is the relevance of the problem under study.

The prevailing ideas about the essence of the internal system for assessing the quality of education, about the criteria and factors determining this system, about the difficulties of making managerial decisions on improving the quality of education were revealed as a result of the interview with 50 heads of educational institutions.

The materials of the article are of practical value for designing a technological model of an internal system for assessing the quality of education, and will help the heads of educational institutions to take into account the leading factors influencing the results of the educational process.

Keywords: internal system of education quality assessment, criteria, indicators, factors affecting the quality of education.

\author{
Гумерова Марина Миннегалиевна \\ К.п.н., дочент, Набережночелнинский государственный \\ педагогический университет \\ roelg@mail.ru \\ Халиуллина Гульназ Самигулловна \\ Аспирант, Набережночелнинский государственный \\ педагогический университет \\ haliullina.1977@mail.ru
}

Аннотация: Актуальность исследуемой проблемы обусловлена, с одной стороны, необходимостью реализации законодательных требований по обеспечению высокого уровня качества образования, а с другой стороны, непроработанностью механизмов, инструментов организации внутренней системы оценки качества образования.

Опрос 50 руководителей образовательных организаций показал сложившиеся представления о сути внутренней системы оценки качества образования, критериях, факторах, обуславливающих ВСОКО, трудностях принятия управленческих решений по вопросам повышения качества образования.

Материалы статьи представляют практическую ценность для проектирования технологической модели внутренней системы оценки качества образования и учета руководителями образовательных организаций ведущих факторов, влияющих на результаты образовательного процесса.

Ключевые слова: внутренняя система оценки качества образования, критерии, показатели, факторы, влияющие на качество образования.
$\Pi$ роблема оценки качества образования является одной из приоритетных задач современной педагогики.

Президент России 24 августа 2011 г. в своем выступлении на собрании с активом Российского союза ректоров подчеркнул необходимость укрепления и полного использования результатов качественного современного образования как стратегического ресурса развития страны и как основы самореализации личности.

Согласно ст. 2 гл. II Федерального закона «Об образовании» № 273-Ф3 основным требованием подтверждения качества образования является соответствие результативных и процессуальных характеристик деятельности образовательных организаций требованиям федеральных государственных образовательных стандартов [2].

Порядок проведения самообследования ОО утвержден приказом Минобрнауки России от 14.06.2013 № 462
«Об утверждении Порядка проведения самообследования образовательной организацией.

В Письме от 16.07.2012 №05 - 26802012 г. Рособрнадзора «О направлении методических рекомендаций по организации и проведению органами исполнительной власти субъектов Российской Федерации, осуществляющими переданные полномочия Российской Федерации в области образования в ОУ, реализующих ООП начального общего, основного общего, среднего (полного) общего образования» указывается на необходимость оценки, в том числе и результатов внутреннего мониторинга качества образования в образовательном учреждении, а также описаны оценочные параметры, охватывающие и качество содержания учебы, и качество условий, и качество результатов.

Показатели эффективности образовательной деятельности установлены приказом Минобрнауки России от 10.12.2013 № 1324 «О показателях деятельности ОО, подлежащей самообследованию». 
Внутренняя система оценки качества образования (далее - ВСОКО) как один из показателей качества обучения стимулирует поиск новых организационно-управленческих механизмов, инструментов, ориентиров обеспечения функционирования мониторинга такого типа [1].

Цель внутришкольной системы оценки качества образования -сбор данных по самообследованию для последующего анализа и принятия управленческих решений по повышению качества образовательного процесса, и для последующего информирования заказчиков и потребителей о степени соответствия качества образовательных услуг требованиям ФГОС.

В педагогической практике существует проблема недостаточности научно-методологического обоснования порядка, содержания, механизма, инструментов, форм и средств организации внутренней системы оценки качества образования. Образовательные организации самостоятельно формулируют цели, задачи, принципы и порядок внутренней системы критериев оценки качества образования.

Актуальной управленческой задачей является необходимость обеспечения понимания идеологии и методологии Внутренней системы оценки качества образования, а на технологическом уровне механизмов и инструментов организации работы по ВСОКО, по изучению ресурсов и нормативно-правовых, организационных, психолого-педагогических условий, обеспечивающих высокий уровень качества образования [3].

Для выявления проблем, связанных с организацией ВСОКО образования был проведён опрос директоров Мензелинского и Тукаевского муниципальных районов Республики Татарстан.

Для анализа уровня информированности руководителей о проблемах внутренней системы оценки качества образования была разработана анкета, включающая вопрос на знание терминологии ВСОКО; открытый вопрос о наиболее важных критериях оценивания ВСОКО; открытый вопрос о преобладающих факторах влияния на ВСОКО; на выявление мнения руководителей о предполагаемых трудностях по принятию управленческих решений по повышению качества образования.

Общее число респондентов составило 50 человек, в том числе, 26,67 \% женщин и 73,33 \% мужчин. Стоит отметить, что все опрошенные проживают в сельской местности или в районном центре.

Наибольшее количество (36\%) участников опроса представлено управленцами со стажем работы от 4 до 7 лет на руководящих должностях. Доля начинающих ди- ректоров и управленцев со стажем более 16 лет составила $13 \%$.

Анализ ответов директоров школ показал наличие существенных затруднений в понимании значимости и технологии организации внутренней системы оценки качества образования. Основной причиной неполного понимания сути ВСОКО является смещение фокуса внимания управленца на решение хозяйственных вопросов и увеличение задач на контроль деятельности управляемой системы.

По результатам ответов руководителей на вопрос: «По каким критериям оценивается ВСОКО в образовательной организации?» - было выявлено восемь наиболее часто встречающихся вариантов, что позволило выделить функционально-организационное ядро параметров ВСОКО, включающее три группы наиболее значимых показателей: качество условий; качество содержания (программ, процессов); качество результатов. Причем на значимость такого критерия оценки как «качество условий реализации ООП» указало большинство респондентов (92\%). Данный факт свидетельствует о наличии определённых сложностей управляющей деятельности руководителя по обеспечению условиями, влияющими на качество образования.

23\% респондентов считают родительскую заинтересованность важным критерием ВСОКО. В то же время $6 \%$ руководителей связывают качество образования с эффективностью управленческой деятельности. Считаем заслуживающими внимание такие устанавливаемые директорами критерии ВСОКО, как «степень открытости деятельности школы» и «качество организации работы по сохранению и укреплению здоровья учащихся». Вместе с тем возникает необходимость в конкретизации показателей предлагаемых критериев ВСОКО в соответствии с измеримыми характеристиками.

Факторы, обуславливающие и процесс и результативность достижения образовательных целей, можно разделить на внешние и внутренние. В целом, преобладающим влиянием, по мнению большинства респондентов, обладают внутренние факторы.

Среди внешних факторов директора образовательных организаций со стажем более 15 лет на руководящих должностях выделяют такие факторы, как «требования законодательства» (14\%) и «актуальные векторы развития современной системы российского образования» (21\%), справедливо полагая, что современные тенденции развития российской системы образования, принятие и реализация законов в данной сфере образования, определяет и критериальную основу ВСОКО.

По мнению опрошенных руководителей, среди вну- 
тренних факторов в наибольшей степени способствуют достижению высокого качества образования следующие:

- «уровень подготовки учителей» (94\%);

- «материально-техническое обеспечение» (96\%);

- «информационно-методическое обеспечение» (82\%).

Данные факты подтверждают наличие проблемы по обеспечению условий реализации образовательных программ.

«Качество образовательных программ» как ведущий фактор ВСОКО выделили 62\% опрошенных. Также значимым фактором, от которого зависит результативность образовательного процесса, с точки зрения 43\% руководителей, является воспитательная работа. Вместе с тем стоит отметить, что «качество результатов» управленцы не рассматривают как фактор, влияющий на качество образования.

Низкий выбор таких факторов, как «реалистичность требований, норм и показателей качества образования» (13\%), «учёт индивидуальных особенностей развития отдельных обучающихся при оценке результатов их образования» (15\%) и «открытость, прозрачность процедур оценки качества образования» (15\%) говорят о том, что среди ряда управленцев существует проблема не понимания сути ВСОКО, слабый уровень знаний норм российского законодательства в сфере образования, в частности, того, что после принятия Федерального закона № 273-Ф3 с 2012 года, образовательная организация в праве самостоятельно принимать все критерии, нормы, требования качества образования.

Таким образом, как считают управленцы-практики, условия реализации ООП являются основным фактором, влияющим на ВСОКО образовательной организации.

95\% руководителей образовательных организаций отмечают острую проблему нехватки педагогических кадров или недостаточно высокий профессиональный уровень педагогического состава. Отсутствие современной материально-технической базы школы, «цифровой разрыв» между сельскими школами и информационнообразовательной средой городских учебных заведений способствуют интенсификации миграционных процессов наиболее активных и успешных слоев населения. Что, в свою очередь, затрудняет использование новых информационно-коммуникационных технологий, тормозит дальнейшее развитие цифровой педагогики и, в целом, отрицательно сказывается на качестве структуры обучения и организации образовательного процесса.

Еще одну проблему о «наличии обучающихся, не осваивающих образовательные программы» поднимают управленцы (23\%). Трудность возникает из-за отсутствия согласия от родителей на перевод на адаптированные ООП в связи с академической неуспеваемостью обучающихся согласно заключению ПМПК и рекомендациям специалистов.

Приведенные выше данные свидетельствуют о том, что наиболее важным критерием внутренней системы оценки качества образования руководители образовательных учреждений считают условия реализации образовательных программ, а именно условия кадрового обеспечение образования (95\%). По мнению большинства опрошенных руководителей вышеназванные факторы, определяют основные проблемы в повышении качества образования.

Среди ответов на вопрос «Какие управленческие решения необходимо принять для повышения качества образования в вашей образовательной организации?» в рейтинг наиболее значимых вошли следующие предложения:

- следовать актуальным векторам развития современной системы российского образования;

- обеспечить повышение уровня психолого-педагогической подготовки учителей путем самообразования, участия в семинарах, профессиональных конкурсах;

- обеспечить качественную систему повышения квалификации педагогического состава (в том числе создание условий для постоянного самообразования);

- обеспечить организационные условия для методического совершенствования педагогов с целью повышения их психолого-педагогической, методической и цифровой компетентности;

- обеспечить реализацию программы работы с детьми, испытывающими трудности в обучении, и их родителями (выстраивание индивидуальных образовательных траекторий);

- обеспечить внедрение и научно-методическое сопровождение по освоению педагогических технологий по формированию метапредметных результатов как основы успешной учебной деятельности;

- формировать у всех субъектов образовательного процесса (руководителей, педагогов, учащихся, родителей) устойчивую мотивацию и осознание ценности «здоровья» как основы реализации целей самосовершенствования и саморазвития;

- обеспечить достойную материально-техническую базу сельским образовательным организациям.

По мнению руководителей сельских образовательных учреждений на внутреннюю систему оценки качества образования влияют отсутствие или недостаточный уровень профессиональной подготовки педагогических 
кадров; недостаточный уровень управленческой компетентности по вопросам правового и нормативно-документационного обеспечения; отсутствие современного технического оснащения в образовательных учреждений; низкий уровень осведомленности и образованности родителей обучающихся сельской местности. Основной проблемой директора сельских школ считают качество условий, влияющих на успешное обучение и профессиональное развитие.

Таким образом, организация ВСОКО является одним из инструментов управления функционированием и развитием образовательной организации. Обеспечение оптимального функционирования внутренней системы оценки качества образования позволит принимать обоснованные управленческие решения.

\section{ЛИТЕРАТУРА}

1. Бобкова Е.Ю., Магсумов Т.А., Максимов Я.А. Актуальные проблемы применения профессиональных стандартов в системе образования // Освітні інновації: філософія, психологія, педагогіка Матеріали III Міжнародної науково-практичної конференції. 2016. С. 140-144.

2. Магсумов Т.А. Современное состояние историко-педагогических исследований // Современные исследования социальных проблем (электронный научный журнал). - 2013. - № 5. - С. 35.

3. Магсумов Т.А. Учащаяся молодежь в общественной жизни Казани начала XX века // В мире научных открытий. - 2011. - Т. 16. № 4. - С. 50-58.

4. Письмо от 16.07.2012 №05 - 26802012 г. Рособрнадзора «0 направлении методических рекомендаций о проведении федерального государственного контроля качества образования в образовательных учреждениях». - Режим доступа: http://obrnadzor.gov.ru.

5. Федеральный закон от 29.12.2012 № 273 - Ф3 «0б образовании в Российской Федерации». - Режим доступа: http://www.consultant.ru/document.

6. Халиуллина, Г.С. Так ли важна для системы образования команда качества / Г.С.Халиуллина, М.М.Гумерова // Роль и значение науки в обществе и ее влияние на инновационное развитие. Сб.статей Международной научно-практической конференции. - Магнитогорск, 2020. - С.232-234.

7. Magsumov T.A. Family and school in Russia at the beginning of the 20th century: attempts to bridge the gap // European Journal of Contemporary Education. 2017. - T. 6. № 4. - C. 837-846.

8. Magsumov T.A. Ideas and meanings of symposium of historians of Russian education // Журнал министерства народного просвещения. - 2015. - № 4 (6). C. 143-145. D0l: 10.13187/zhmnp.2015.6.143

( Гумерова Марина Миннегалиевна (roelg@mail.ru), Халиуллина Гульназ Самигулловна (haliullina.1977@mail.ru).

Журнал «Современная наука: актуальные проблемы теории и практики»

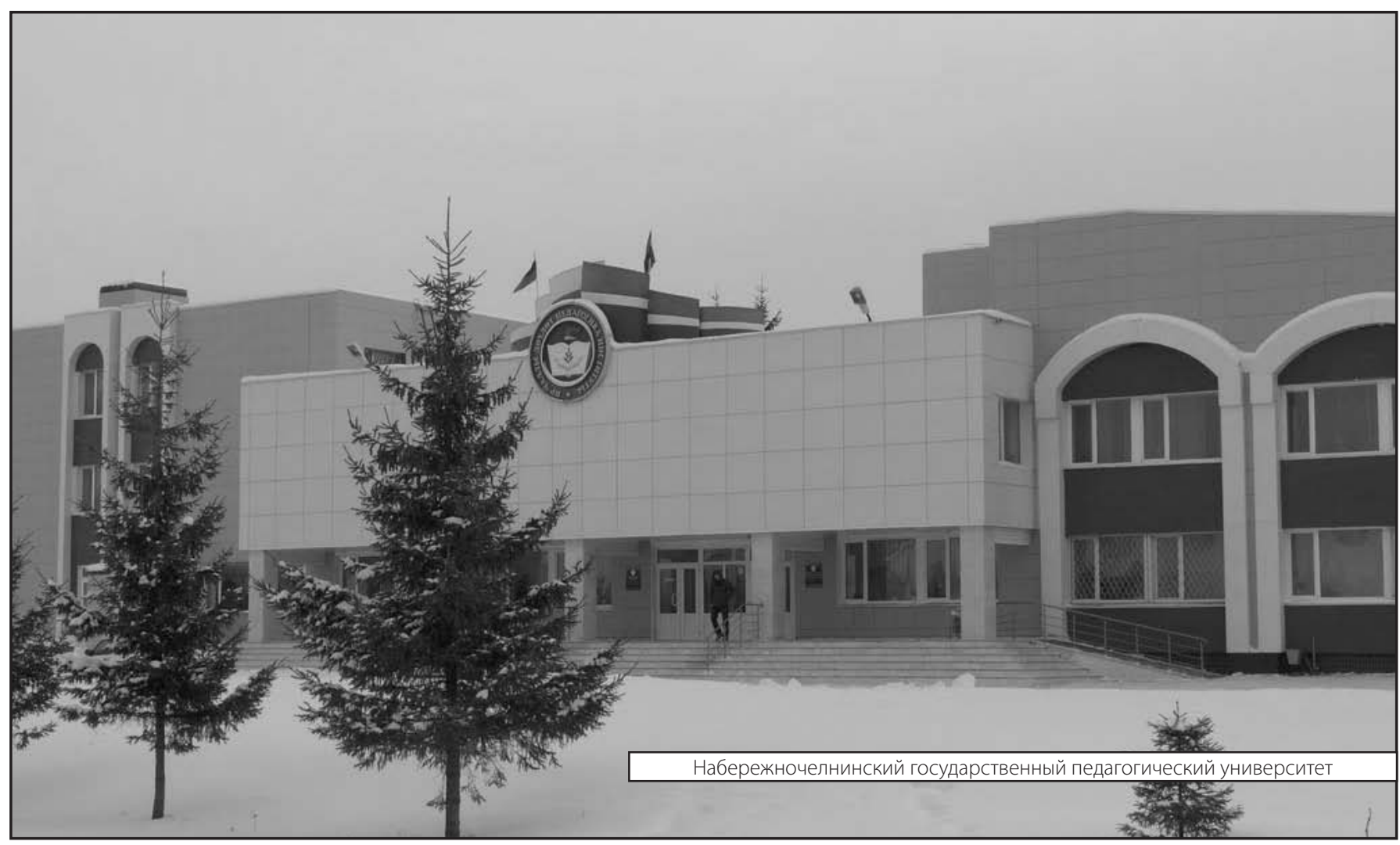

